\title{
Correction to: Semi-Solid Metal (SSM) Technologies
}

\section{Correction to:}

\section{S. Nafisi, R. Ghomashchi, Semi-Solid}

Processing of Aluminum Alloys, https://doi.org/10.1007/978-3-319-40335-9_2

The Chapter was inadvertently published with incorrect figure (Fig. 2.26). The same has been corrected in the chapter.
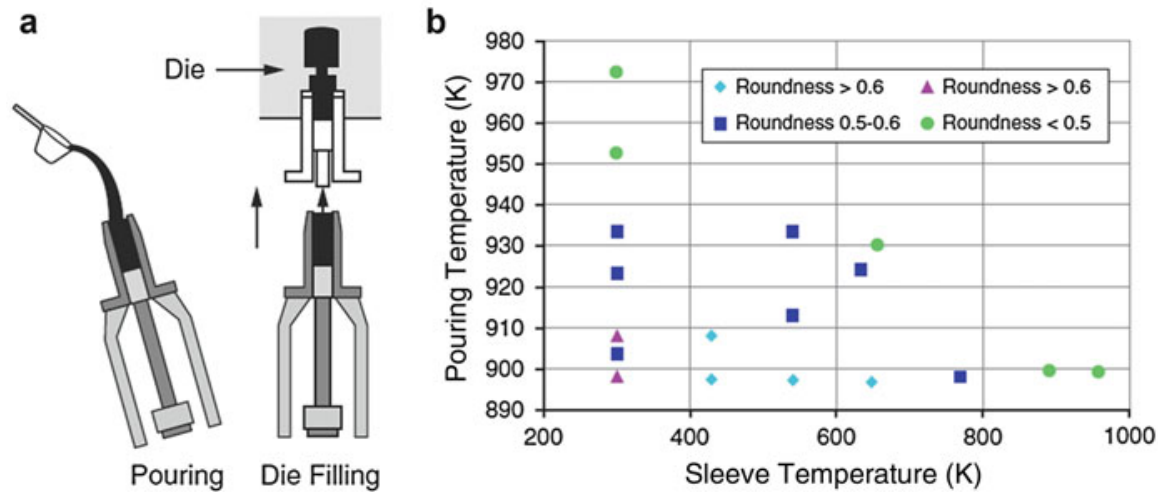

The updated online version of this chapter can be found at https://doi.org/10.1007/978-3-319-40335-9_2 